\title{
Anaerobic metabolism and oxygen distribution in the carbonate sediments of a submarine canyon*
}

\author{
G. M. King ${ }^{1, * *}$, R. G. Carlton ${ }^{2}$, T. E. Sawyer ${ }^{1}$ \\ ${ }^{1}$ Darling Marine Center, University of Maine, Walpole, Maine 04573, USA \\ ${ }^{2}$ Kellogg Biological Station, Michigan State University, 3700 Gull Lake Drive, Hickory Corners, Michigan 49060, USA
}

\begin{abstract}
Microelectrodes were used in situ to measure the distribution of oxygen in the organicpoor, carbonate sediments of a tropical submarine canyon and in sediments from a shallow organicenriched bay. Analyses of sulfate reduction, nitrogen fixation (acetylene reduction), and several porewater and bulk sediment parameters were conducted in parallel. Oxygen penetration was generally limited to depths of 5 to $10 \mathrm{~mm}$ with occasional penetration to greater depths related to turbulence in the water column. Oxygen supersaturation at the sediment-water interface or at depths of a few millimeters indicated that benthic photosynthesis contributed in part to the controls of oxygen distribution. Highest rates of sulfate reduction were usually observed between 1 and $3 \mathrm{~cm}$ depths. Rates of sulfate reduction integrated over a $10 \mathrm{~cm}$ interval were higher in the bay than canyon sediments, which was consistent with differences in organic content. There was also a correlation between integrated rates of reduction and the presence of surface algal films as indicated by chlorophyll concentrations. Trends similar to those for sulfate reduction were observed for the distribution of solid-phase reduced sulfur species and for acetylene reduction.
\end{abstract}

\section{INTRODUCTION}

In spite of a limited data base, several lines of evidence suggest that anaerobic metabolism is important in the nutrient cycles of tropical carbonate sediments. For instance, Williams et al. (1985) have proposed that a significant fraction ( $>20 \%$ ) of the sediments in Teague Bay, U.S. Virgin Islands are anoxic; our own data suggest that large areas of the sediment surface are suboxic, especially at night, and that anoxia predominates at depths greater than about $1 \mathrm{~cm}$. Others have measured significant rates of sulfate reduction (e.g. Skyring \& Chambers 1976, Hines \& Lyons 1982, Skyring 1985; see also Skyring 1987 for a pertinent literature review), nitrogen fixation (e.g. Patriquin \& Knowles 1975, Corredor \& Capone 1985, O'Neil \& Capone 1989; see also Capone 1988 for a pertinent literature review) or observed endproducts of

- Contribution nos. 209 from the Darling Marine Center, 644 from the Kellogg Biological Station, and NURC-FDU J-474 from WIL/NURP (West Indies Laboratory/National Undersea Research Program)

- Present address: Department of Ecology and Genetics, University of Århus, Ny Munkegade Bldg 550, DK-8000 Århus C, Denmark anaerobic metabolism such as hydrogen sulfide in reef sediment porewaters (e.g. Waslenchuk et al. 1983, Pigot \& Land 1986). Data from these studies have clearly shown that anaerobic processes are an important component of benthic heterotrophic metabolism. Skyring (1985) estimated that sulfate reduction could account for up to $20 \%$ of the organic carbon oxidation in lagoon sediments from Davies Reef, Australia.

During a saturation diving mission in a submarine canyon near St. Croix, U.S. Virgin Islands, a preliminary survey with microelectrodes revealed substantial oxygen depletion (maximum penetration $15 \mathrm{~mm}$ ) in coarse-grained carbonate sediments with low organic carbon concentrations (King \& Carlton unpubl.). These results were significant because they indicated that anaerobic metabolism occurred within an extensive sediment volume. Earlier, Entsch et al. (1983) and Williams et al. (1985) used redox electrodes to show that reducing conditions in coral reef sediments occurred below about $5 \mathrm{~cm}$; anoxia can be inferred from their data to have occurred within a few centimeters. Patriquin \& Knowles (1975) indicated that anoxic microzones probably occurred in oxidized sediments, particularly in microenvironments such as foraminiferan tests. 
We report here a detailed analysis of oxygen distribution, sulfate reduction and nitrogen fixation (acetylene reduction) in sediments from several sites within a shallow bay ( 1 to $2 \mathrm{~m}$ depth) and Salt River Canyon (14 to $30 \mathrm{~m}$ depth), including areas colonized by patchy but common algal films. In conjunction with these studies, we examined selected aspects of sediment and porewater chemistry (e.g. chlorophyll content, acid-volatile and chromium-reducible sulfur [pyrite], sulfate, and sulfide). These analyses provide the first microprofiles of dissolved oxygen in the porewaters of coral reef sediments with accompanying estimates of related anaerobic processes.

\section{METHODS}

Site description. The research described below was conducted using the facilities of the National Undersea Research Center on St. Croix, U.S. Virgin Islands. The underwater habitat, 'Aquarius', served as a living and working platform in Salt River Canyon. In addition, surface-based work was conducted in Triton Bay, a small, shallow embayment located near the head of the canyon.

Salt River Canyon is located on the St. Croix shelf, several hundred meters from shore. It is bounded on the west and east by coral reefs (Fig. 1). Canyon depths range from about 10 to $>60 \mathrm{~m}$ but the working range for the research described here was about 15 to $35 \mathrm{~m}$. The canyon sediments are characterized by a silty carbonate sand with generally low organic matter concentrations (ca $0.5 \%$; L. Mayer unpubl.). The upper 5 to $10 \mathrm{~cm}$ are oxidized in appearance with little visual evidence of anoxia or a redox potential discontinuity (sensu Fenchel \& Riedl 1970). Below this interval, sediments have a mottled light grey appearance, probably due to the presence of iron monosulfides. The sediment surface is characterized by patches of algae, primarily diatoms, which occur as a thin 'film' localized at the sediment-water interface. This film is not analogous to the algal mats reported in other studies (e.g. Jørgensen \& Cohen 1977) in that biomass is low and there is no visible striation or structure. In addition, the sediment contains recognizable fragments of seagrass and seaweed detritus. A variety of vertebrates and invertebrates actively rework the sediment from depths of millimeters to tens of centimeters. Notable among these are: Callianassa sp., Mulloidichthys martinicus, Strombas gigas and Urolophus jamaicensis. Additional descriptive information on this system is available from Multer \& Gerhard (1974).

The sediments in Triton Bay differ distinctly from those in the canyon. Although they are largely carbonate, they contain a terrigenous component (silts and clays) derived from the adjacent watershed and from Salt River, an ephemeral input on the south side of the bay. Triton Bay sediments also contain much higher organic concentrations (about 5\%; L. Mayer unpubl.), a distinct oxidized layer $(1$ to $2 \mathrm{~cm})$ and a black, sulfidic layer (ca 1 to $10+\mathrm{cm}$ ). Triton Bay sediments are actively reworked as evidenced by casual observations of burrow densities, but the fauna have not been documented.

Oxygen analyses. The distribution of oxygen in situ was determined using microelectrodes (e.g. Revsbech \& Jørgensen 1986, Carlton \& Wetzel 1987). These electrodes were of the 'Clark' or combination style and had cathode diameters of ca $5 \mu \mathrm{m}$ and overall diameters for the electrode of ca $150 \mu \mathrm{m}$. The electrodes were constructed for robustness in sandy sediments and were

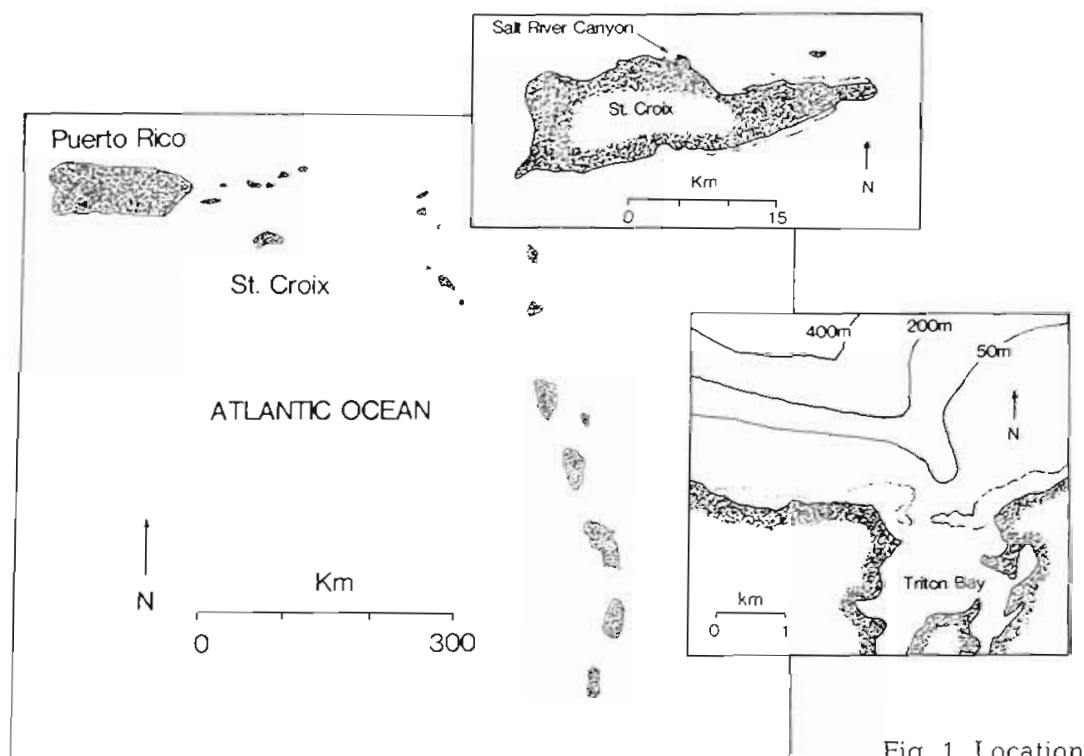

Fig. 1. Location of St. Croix and sampling sites 
therefore somewhat larger than others that have been described (e.g. Carlton \& Wetzel 1987). Spatial resolution could be obtained at distances $<250 \mu \mathrm{m}$ but limitations of in situ field work resulted in a $1 \mathrm{~mm}$ resolution. The in situ oxygen readings were made in 3 ways. First, a microelectrode was connected via waterproof fittings to a battery-powered meter (Keithley 480 picoammeter modified to also supply a polarization voltage of $-0.75 \mathrm{~V}$ to the cathode) in a pressure housing. Data were recorded by hand as the microelectrode was advanced in $1 \mathrm{~mm}$ increments. This method was used at sites distant from the habitat. In a second method, the microelectrode was connected via a $30 \mathrm{~m}$ cable to an oxygen meter (Diamond General Model 1201) inside the habitat. The diver operating the micromanipulator communicated with a second person in the habitat who operated the meter and recorded data. A third method also used microelectrodes on long cables but in this case, the electrode signal was transmitted through an analog-to-digital converter to a microcomputer (Zenith 151) for data storage and subsequent analysis.

In addition to in situ analyses, cores were collected from several sites and returned to the habitat for measurement of oxygen microprofiles. Core samples were stored outside the habitat prior to analysis in order to maintain in situ conditions and to avoid artificial elevation of oxygen concentrations as a result of the hyperbaric atmosphere inside the habitat.

Sulfate reduction. Rates of sulfate reduction were determined using a direct injection technique (e.g. Jørgensen 1977). Cores $(6.5 \mathrm{~cm}$ inner diameter) were first obtained using acrylic tubes with ports drilled at intervals into the side of the tubes. After collection, the cores were returned to the habitat and subsampled with 'cutoff' $5 \mathrm{cc}$ syringes. The syringes were used to collect small undisturbed subcores from depths of 1,3 , 5,7 , and $9 \mathrm{~cm}$. The subcores were sealed with grey butyl serum bottle stoppers (Supelco, Inc.) and then sent to the surface for addition of radiolabel. A solution of carrier-free ${ }^{35} \mathrm{SO}_{4}^{2-}(10 \mu \mathrm{l})$ was injected along the central axis of the subcores which were then incubated for 24 h at ambient seawater temperatures ( 25 to $27^{\circ} \mathrm{C}$ ). The incubation was terminated by freezing. Further processing was conducted in Maine where radiolabelled sulfides were distilled as described in King et al. (1985) and King (1988). For some samples, determinations were made of both acid-volatile sulfides as well as chromium-reducible sulfides (mostly pyrite and elemental sulfur for radiolabel; mostly pyrite for mass).

Nitrogen fixation. Rates of nitrogenase activity were determined using cores and subcores obtained as above. After sealing the subcores, each was injected with $0.4 \mathrm{ml}$ of a solution of acetylene-saturated seawater which was prepared at the surface by vigorous sparging with acetylene. The solution was transferred to a $50 \mathrm{cc}$ syringe with no gas space and sent to the habitat for use. After injection, the acetylene partial pressure was calculated to be about $0.2 \mathrm{~atm}$, equivalent to the pressures normally used for determining nitrogenase activity (e.g. Capone 1988). The subcores were incubated in the habitat at ambient seawater temperature for 12 to $24 \mathrm{~h}$.

Estimates of nitrogen fixation were based on the production of ethylene and are referred to hereafter as 'acetylene reduction'. Measurements of ethylene were made after returning the subcores to the surface. Each subcore was injected into a $10 \mathrm{ml}$ blood collection tube; after rapidly sealing the tube, $0.75 \mathrm{ml}$ of a solution containing ammoniacal silver was injected (David et al. 1980). This procedure resulted in the precipitation of acetylene from the gas phase. Samples of the tube gas phase $(0.2$ to $0.4 \mathrm{ml})$ were obtained with a syringe and needle and injected into a Varian 1400 gas chromatograph fitted with a $2 \mathrm{~m} \times 0.32 \mathrm{~cm}$ OD stainless steel column containing Porpak R (Waters Associates, Inc.). Ethylene was detected with a flame ionization detector, the response of which was analyzed with an HP-3390A recording integrator.

Porewater and sediment analyses. Porewater samples were obtained with an in situ dialysis device (e.g. Hesselin 1976) Ten vertically arrayed chambers had a resolution of about $1.5 \mathrm{~cm}$ over a $15 \mathrm{~cm}$ depth interval. The chambers contained deionized water initially and were fitted with a $0.45 \mu \mathrm{m}$ pore-size membrane made of polysulfone (Gelman, Inc.). An initial study of salinity and sulfate showed that the small chambers (ca $4 \mathrm{ml}$ ) equilibrated rapidly $(<72 \mathrm{~h})$ with porewater; in practice, the chambers were deployed for $96 \mathrm{~h}$. After retrieval, the chambers were returned as quickly as possible to the habitat for sampling. Aliquots for sulfate and sulfide analyses (Cline 1969, Tabatabai 1974, respectively) were injected into blood collection tubes that contained a solution of $5 \%$ zinc acetate; samples for salinity (refractometer) were preserved by freezing.

The chlorophyll content of selected Canyon sediments was determined after extraction with a solution of $90 \%$ acetone $10 \%$ dimethyl sulfoxide. Sediments for extraction were obtained using $50 \mathrm{cc}$ syringe-cores. The cores were subsectioned in the habitat at 1 to $2 \mathrm{~cm}$ intervals; the subsections were weighed and sent to the surface for an extraction that took place overnight in the dark at about $4^{\circ} \mathrm{C}$. The chlorophyll in the extracts was measured spectrophotometrically at 665 and $750 \mathrm{~nm}$ before and after the addition of acid. Absorbance was converted to units of chlorophyll according to Lorenzen (1967).

Sediment water content and bulk density were determined using cores obtained and sectioned as above. The subsections were weighed fresh, dried at $105^{\circ} \mathrm{C}$ for $48 \mathrm{~h}$ and reweighed. 


\section{RESULTS AND DISCUSSION}

\section{Oxygen dynamics}

Oxygen microprofiles in surficial sediments were measured in situ at 3 sites near the 'Aquarius' habitat (depth $=18 \mathrm{~m}$ ) and at a more distant site (depth = $26 \mathrm{~m}$ ). At two of the shallower sites, which received a photosynthetic photon flux density (PPFD) of 300 to $400 \mu \mathrm{E} \mathrm{m}^{-2} \mathrm{~s}^{-1}$, the sand surface was rippled (amplitude $=6$ to $10 \mathrm{~cm}$, period $=40$ to $56 \mathrm{~cm}$ ) as a

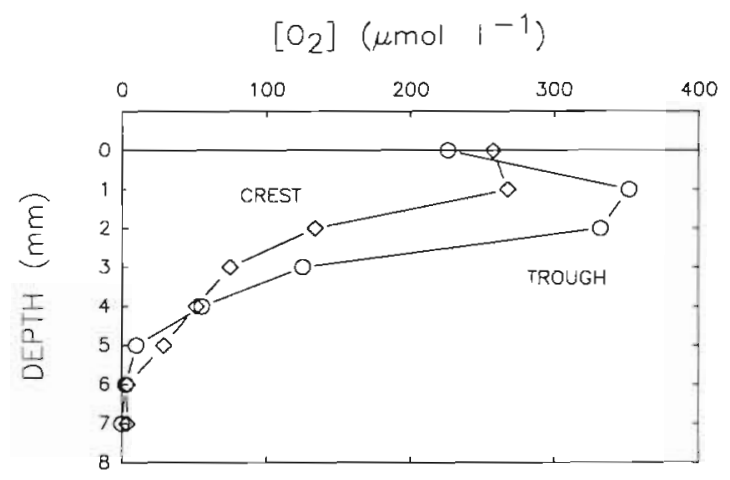

Fig. 2. Vertical distributions of oxygen concentration in crest and trough of surge-generated sand ripples at a water depth of $18 \mathrm{~m}$. PPFD $=370 \mu \mathrm{E} \mathrm{m} \mathrm{m}^{-2} \mathrm{~s}^{-1}$ Points are means of 2 determinations. Ripple period $=56 \mathrm{~cm}$; amplitude $=6$ to $8 \mathrm{~cm}$. Saturation concentration $=210 \mu \mathrm{M}$

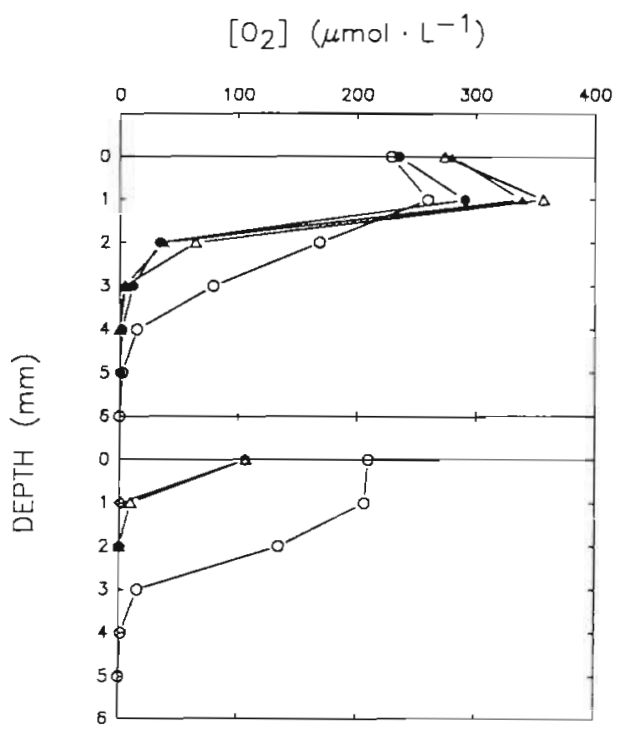

Fig. 3. Vertical distributions of oxygen concentration in sediments at 2 sites within $5 \mathrm{~m}$ of each other. Water depth $=17 \mathrm{~m}$, PPFD $=270$ to $400 \mu \mathrm{E} \mathrm{m}^{-2} \mathrm{~s}^{-1}$ Upper panel: slightly eroded ripples (period $=40 \mathrm{~cm}$, amplitude $<4 \mathrm{~cm}$ ); open symbols: crest, closed symbols: trough. Lower panel: previously rippled sediments disturbed by feeding goatfish ca $2 \mathrm{~h}$ before making measurements. Saturation concentration $=210 \mu \mathrm{M}$ result of weather-induced surge that occurred several days earlier. However, during this series of measurements there were relatively quiescent conditions (e.g. flow velocity $\left.<3 \mathrm{~cm} \mathrm{~s}^{-1}\right\}$. The photosynthetic activity of benthic microalgae (mostly pennate diatoms) resulted in oxygen supersaturation about $1 \mathrm{~mm}$ below the interface, and oxygen penetration to depths of 6 to $7 \mathrm{~mm}$ (Figs. 2 and 3 upper). Several hours before making measurements at the third shallow site, a small school of benthic-feeding goatfish Mulloidichthys martinicus had disturbed the sediment enough to break down the sand ripples, producing a dimpled topography. The effect of the disturbance appeared to be loss of photosynthesis at the interface resulting in shallower oxygen penetration and no zone of supersaturation (Fig. 3 lower). At the $26 \mathrm{~m}$ site, which received a PPFD of about $75 \mu \mathrm{Em}^{-2} \mathrm{~s}^{-1}$, oxygen penetrated only to $4 \mathrm{~mm}-$ even though slight supersaturation occurred at the $1 \mathrm{~mm}$ depth (Fig. 4).

Cores $(5.7 \mathrm{~cm} \mathrm{ID} \times 15 \mathrm{~cm}$ length) taken at depths of $15,18,25$, and $31 \mathrm{~m}$ were returned to the habitat for microelectrode analysis. The hyperbaric atmosphere in the habitat caused elevated oxygen concentrations in the cores relative to ambient seawater after about 45 min. However, cores stored open to ambient seawater for several hours still reflected oxygen conditions in situ (compare Figs. 2 and 5) if profiled rapidly in the habitat. Oxygen concentrations and penetration depths were low in core samples incubated in darkness outside the habitat (Fig. 6). The validity of microelectrode measurements made on stored core samples depended on the hydrodynamic conditions that existed during and prior to sampling. During daytime and quiescent conditions, oxygen distributions were largely a result of the rate of microalgal photosynthesis at the sedimentwater interface. Under these conditions changes during storage were minimal. However, when in situ

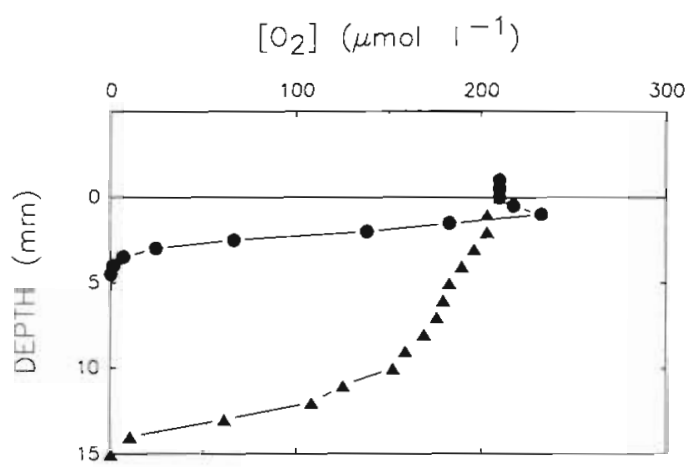

Fig. 4. Vertical distributions of oxygen concentration in sediments exposed to different hydrodynamic and illumination

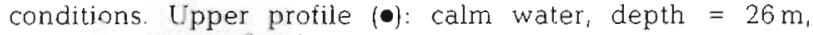
$\mathrm{PPFD}=75 \mu \mathrm{Em} \mathrm{m}^{-2} \mathrm{~s}^{-1}$. Lower profile $(\mathbf{\Delta})$ : reciprocating surge causing sand movement at interface, depth $=16 \mathrm{~m}$, PPFD $=$ $300 \mu \mathrm{E} \mathrm{m} \mathrm{m}^{-2} \mathrm{~s}^{-1}$. Saturation concentration $=210 \mu \mathrm{M}$ 
water movements near the interface were turbulent, even short-term storage of cores (i.e. isolation of the sample from natural turbulence) resulted in altered oxygen distributions and concentrations.

The effect of turbulence was especially evident during a period of relatively high water movement in 1985 ('Hydrolab' Mission 85-2). At this time, in situ analyses showed oxygen penetration to depths exceeding $15 \mathrm{~mm}$ in well-illuminated, diatom-colonized sediments (Fig. 4). However, in spite of an apparently active photosynthetic community, there was no zone of supersaturation. This lack of a localized photosynthetic effect was probably due to a high degree of advection. These results contrast greatly with trends observed during 1988 when, because of unusually calm weather, advective dominance of oxygen dynamics was seldom observed and supersaturation at the sediment surface was more common. On the continuum between low and high velocity of water movements near the sedimentwater interface, there appears to be a transition point (or region) for the factors that control sediment oxygen dynamics. At the lower end of the scale the concentrations and distributions of oxygen are dominated by relative rates of photosynthesis and respiratory consumption, leading to large differences in oxygen distributions between day and night. At velocities above the point of transition the advective flux of water across the interface becomes sufficient to mix and dilute oxygen-enriched or depleted zones with ambient water and drive it into deeper sediment layers. Thus under turbulent conditions no differences in oxygen distributions should be observed between day and night.

Chlorophyll $a$ in the upper $1 \mathrm{~cm}$ of sediment varied from 46 to $109 \mathrm{mg} \mathrm{m}^{-2}$ at the various sites sampled, but did not correlate with oxygen penetration depths or maximum oxygen concentrations. Conversely, light

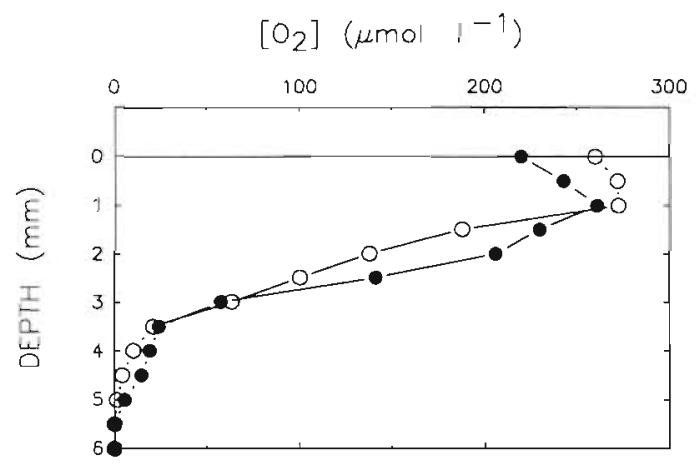

Fig. 5. Vertical distributions of oxygen concentration in 2 sediment core samples taken at a depth of $15 \mathrm{~m}$. Measurements made inside the 'Aquarius' habitat. PPFD $=100 \mu \mathrm{E} \mathrm{m}^{-2}$ $\mathrm{s}^{-1}$ Saturation concentration $=210 \mu \mathrm{M}$ intensity correlated strongly with both features of the oxygen microprofiles (see Fig. 6). An exception was a site near the habitat that was subjected to repeated disturbance by goatfish grazing. This site had the lowest chlorophyll a values among all sites; in addition, oxygen penetration (Fig. 3 lower) during daytime (in 2 of the 3 measured microprofiles) was less than in some other sites during darkness. Reasons for this pattern are not yet clear and are the subject of further investigation.

\section{Sulfate reduction}

The limited penetration of oxygen provided an environment suitable for sulfate reduction. However, rates in the canyon were relatively slow (2 to $5.6 \mathrm{mmol}$ $\mathrm{S} \mathrm{m}^{-2} \mathrm{~d}^{-1}$ ) although they were similar to rates from other tropical systems low in organic carbon (Table 1). Rates from Triton Bay were higher than those in the Canyon $(2.2$ to $7.7 \times)$ and more comparable to the results of Hines \& Lyons (1982) for shallow lagoons in Bermuda. However, it must be noted that only the data of Skyring (1985) are directly comparable to the work presented here since all other studies of carbonate systems have used procedures which do not quantitatively recover the radiolabelled sulfide formed during the sulfate reduction analysis. Thus other reported rates may be underestimates.

One important feature of sulfate reduction in the canyon was its variability among sites. Lowest rates were found in sediments that had no obvious surface algal film; rates were higher by a factor of about 2.3 to 2.8 where an algal film was evident; rates were also higher $(1.6 \times)$ at a site of detritus deposition along the west wall of the canyon at a depth of $28 \mathrm{~m}$ (Table 1;

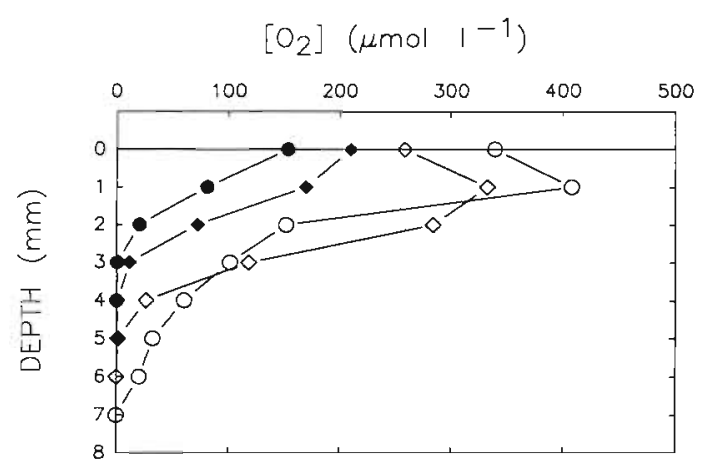

Fig. 6. Vertical distributions of oxygen concentration during darkness (closed symbols) and during exposure to $100 \mu \mathrm{E} \mathrm{m}^{-2}$ $s^{-1}$ PPFD (open symbols) in 2 sediment core samples taken from a depositional zone near the canyon wall at a depth of $30 \mathrm{~m}$. Measurements made inside the 'Aquarius' habitat. Saturation concentration $=210 \mu \mathrm{M}$ 
Fig. 7). Since sulfate reduction rates in 0 to $2 \mathrm{~cm}$ depth interval were correlated with total pigment concentrations (Fig. 8; rate $=-12.8+36.7 \times$ total pigment, $\mathrm{I}=0.96)$, it is possible that some of the differences among sites were due to a relatively close coupling between algal production and heterotrophic metabolism. However, since integrated rates of sulfate reduction (e.g. rates per $\mathrm{m}^{2}$ ) did not correlate with chlorophyll, benthic primary production may not be the major factor controlling the patterns of sulfate reduction within the canyon. Instead, patterns may be controlled by small-scale patchiness in organic inputs and the burial of macroalgal and macrophytic detritus originating from the seagrass and seaweed beds at the head of the canyon.

A methodological point of importance concerned the distribution of radiolabel during the sulfate reduction analyses. The label recovered by a simple acid distillation ranged from 15 to $38 \%$ of the total reduced label and correlated well with sulfate reduction rates $(\mathrm{r}=$ 0.97 ). This correlation did not provide an explanation for the label distribution, but may have indicated the extent to which rates reported by others for similar sites could be in error. Thode-Andersen \& Jørgensen (1989) have also observed a positive correlation between sulfate reduction rates and the amount radiosulfide present in the acid-volatile fraction. However, in the clastic coastal sediments they examined, acid-volatile sulfides were a greater fraction of the total reduced label for sediments with sulfate reduction rates comparable to those reported here.

The amount of acid-volatile radiolabel formed within

Table 1. Comparison of sulfate reduction rates in shallow marine carbonate sediments. Data from St. Croix are based on depth profiles integrated over 0 to $10 \mathrm{~cm}$

\begin{tabular}{|lcl|}
\hline Site & $\begin{array}{c}\text { Rate } \\
\text { (mmol S m }\end{array} \mathrm{d}^{-1}$ ) & \multicolumn{1}{c|}{ Source } \\
\hline $\begin{array}{l}\text { St. Croix: } \\
\text { uncolonized } \\
\text { detritus deposit }\end{array}$ & 2.0 & This study \\
algal film & 3.3 & \\
Triton Bay, Thallassia & $4.5-5.6$ & \\
Triton Bay, muddy & 15.4 & \\
Bermuda: & 12.3 & \\
$\quad$ Coot Pond & & Hines \& Lyons \\
Mangrove Bay & $14-24$ & (1982) \\
Devils Hole & $18-28$ & \\
Australia: & 0.4 & \\
Lizard Island & & Skyring \& \\
Davies Reef & 2.0 & Chambers (1976) \\
\hline
\end{tabular}

any given sediment may reflect parameters such as porewater and solid-phase sulfide concentrations (Thode-Andersen \& Jørgensen 1989). Low sulfide concentrations have been associated with low acid-volatile radioactivity in salt marshes (e.g. King et al. 1985, King 1988 ) as well as subtidal coastal sediments (ThodeAndersen \& Jørgensen 1989). This relationship is probably due in part to the rapid isotopic exchange which occurs among dissolved sulfide, elemental sulfur, pyrite and other sulfur-containing species (Fossing \& Jørgensen in press). The very low to undetectable dissolved sulfide concentrations in the canyon porewaters may have favored the exchange of radiolabelled sulfide with non-volatile sulfur species (e.g. elemental sulfur and pyrite) and limited the accumulation of acid-volatile label relative to other sediments.

Stable solid-phase sulfur pools in the sediment provided other insights into the behavior of reduced sulfur.

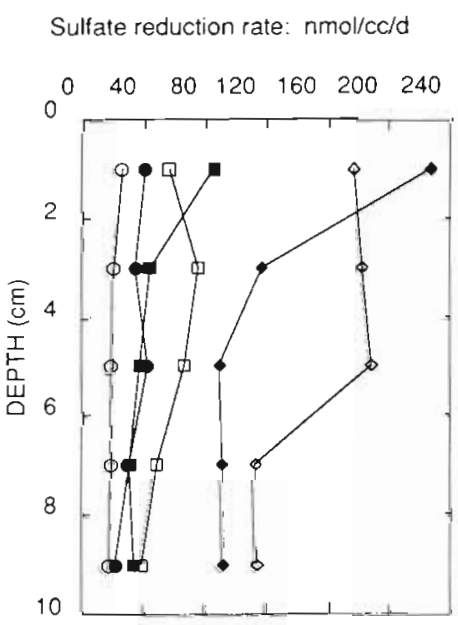

Fig. 7. Depth profiles of sulfate reduction rates; rates are means of triplicate samples. Symbols as follow: (*) Triton Bay muddy site; ( $)$ Triton Bay seagrass site; ( $)$ Salt River Canyon, bare sediment; (-) Salt River Canyon, algal-film covered sediments 1 and 2 ; (口) Salt River Canyon, detritus deposition site

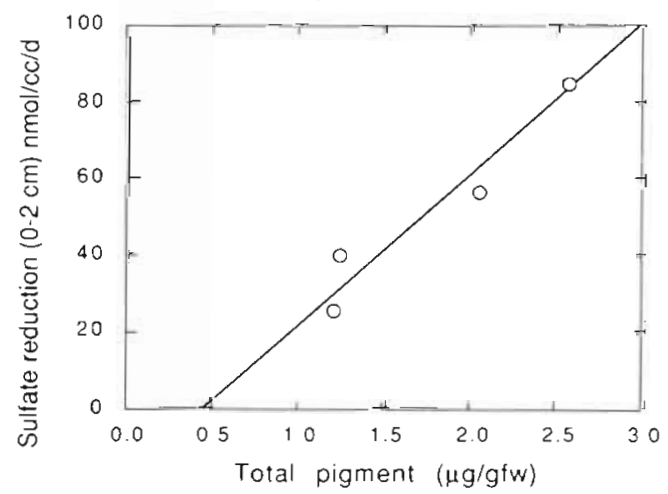

Fig. 8. Sulfate reduction rates in the $0-2 \mathrm{~cm}$ interval of sites within Salt River Canyon versus total pigments in the same interval; data are means of triplicate determinations for sulfate reduction and duplicates for pigments 
For example, acid-volatile sulfide concentrations were higher at sites with algal films or detritus deposition than the canyon site with no algae; the highest acidvolatile sulfide concentrations were observed in Triton Bay where values were about 4.4 to $10.3 \times$ values in the canyon. In general, sites with higher sulfate reduction rates had higher concentrations of acid-volatile sulfides, a trend reported by others (e.g. Skyring 1987). Similar trends were observed for total reduced sulfur (Fig. 9). A regression analysis between total reduced sulfur and sulfate reduction rates suggested a good predictive relationship (Fig. 10; total reduced sulfur $=$ $-3.0+$ rate $\times 1.08, r=0.97$ ). The canyon sites were somewhat variable, but collectively formed a cluster whose aggregate rates and total reduced sulfur were consistent with the 2 Triton Bay sites.

Although the various sulfur pools are correlated with sulfate reduction rates, estimates of turnover times $\left(T_{t}\right)$

Total reduced inorganic sulfur ( $\mu \mathrm{mol} / \mathrm{gdw})$

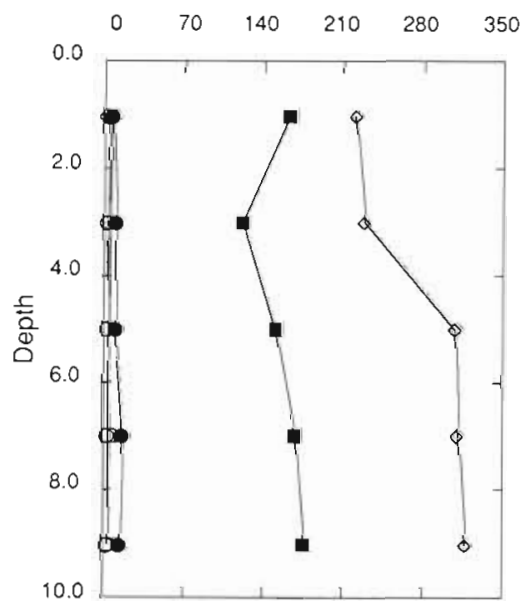

Fig. 9. Depth profiles of total reduced inorganic sulfur (acidvolatile sulfides and pyrite). ( $\diamond)$ Triton Bay, muddy site (triplicates); (-) Triton Bay seagrass site (triplicates); (o) Salt River Canyon, bare sediment; $(\bullet)$ Salt River Canyon, algal-film covered sediments (quadruplicates); ( $\sqcup$ ) Salt River Canyon, detritus deposition site (duplicates)

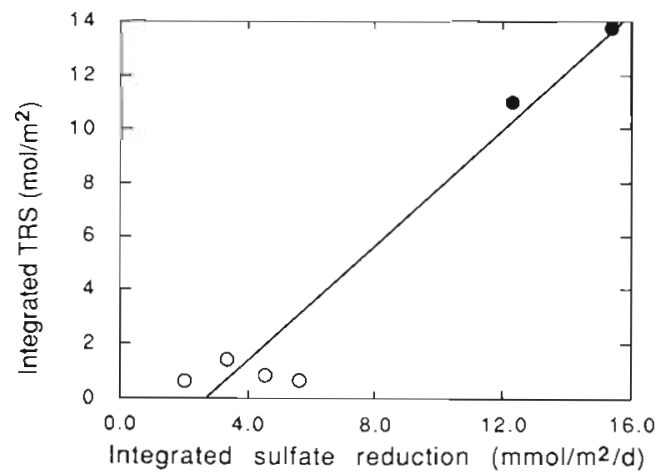

Fig. 10. Depth-integrated total reduced inorganic sulfur versus integrated sulfate reduction rates $(0-10 \mathrm{~cm})$; (•) Triton Bay; (o) Salt River Canyon suggest that there are some differences between sites in the extent or controls of sulfur burial. $T_{t}$ is estimated by dividing the depth-integrated total sulfur pool $(0$ to $10 \mathrm{~cm}$ ) by the depth-integrated sulfate reduction rate. This calculation provides a simple picture of potential turnover. The $T_{t}$ data are consistent with a more rapid reduced sulfur turnover in the canyon (146 to 446 d) than Triton Bay ( 894 to 897 d). The differences in turnover between sites could be due to differences in oxygen dynamics and the availability of iron among other possibilities. For example, the relative amount of sulfide oxidation in the canyon may be greater since oxygen penetrates deeper than in Triton Bay sediments (Carlton unpubl.). Higher iron concentrations in Triton Bay sediments may promote the incorporation of a greater fraction of total sulfide production into solidphase sulfides thereby resulting in a decrease in the relative lability of the total reduced sulfur pool.

\section{Acetylene reduction}

Rates of acetylene reduction were estimated from the accumulation of ethylene in sealed, undisturbed 'minicores'. A time-course analysis indicated that ethylene formation occurred without lag and was linear for $24+\mathrm{h}$. As a consequence, single time point incubations were used for determining the distribution of acetylene reduction at sites in the canyon and Triton Bay.

In general, the distribution and rates of acetylene reduction paralleled trends for sulfate reduction; rates were typically highest in Triton Bay and in samples with algal films (Fig. 11; Table 2). A regression analysis indicated that acetylene reduction and sulfate reduction were closely correlated (Fig. 12; acetylene reduction $=0.18+$ sulfate reduction $\times 0.03, \mathrm{r}=0.88$ ) . The correlation could have resulted from common controls (e.g. organic matter) or from the presence of nitrogen-fixing sulfate reducers which dominated ethylene production. Several investigators have previously concluded for a variety of reasons that sulfatereducing bacteria are the predominant nitrogen-fixers in marine sediments (Dicker \& Smith 1980, Nedwell \& Azin bin Abdul Aziz 1980, Postgate 1982a, b, Capone 1988). The higher rates of nitrogenase activity as well as sulfate reduction in Triton Bay were probably due to greater availability of substrates, either from Thalassia directly for sediments in the seagrass beds (as suggested by Capone \& Taylor 1980 and Capone 1982) or from diverse marine and terrestrial sources in the Bay itself.

The observed rates and depth profiles were similar in magnitude and form to those reported from other tropical, carbonate systems (Table 2; Capone \& Taylor 1980, O'Neil \& Capone 1989). However, it is difficult to make 
any firm comparisons since methods differed significantly among studies and since Capone \& Carpenter (1982) demonstrated that the use of slurries may result in underestimates of fixation relative to less intrusive methods. In addition, O'Neil \& Capone (1989) have reported that vigorous physical mixing can decrease rates.

Due to the lack of simultaneously measured nitrogen pools, fluxes, and fixation rates, the importance of nitrogen fixation for the benthic nitrogen cycle cannot be estimated quantitatively. However, porewater analyses from a subsequent sampling during March 1989 (Blackburn pers. comm.) have revealed relatively low ammonia pool sizes ( 5 to $15 \mu \mathrm{M}$ ) that are similar in magnitude to those reported by others (e.g. Williams et

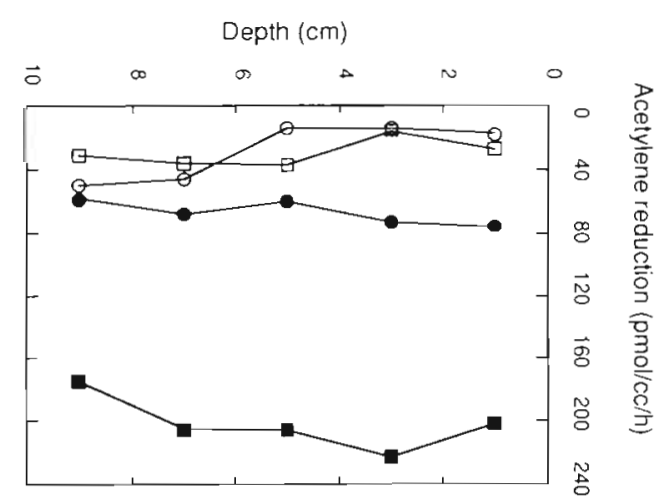

Fig. 11 Depth profiles of nitrogenase activity (acetylene reduction rates). (-) Triton Bay seagrass site; (c) Salt River Canyon, bare sediment; $\bullet$ Salt River Canyon, algal-film covered sediment 1; ( $)$ Salt River Canyon, detritus deposition site

Table 2. Comparison of nitrogen fixation rates in selected marine sediments. The estimates from St. Croix are based on integrated depth profiles of acetylene reduction activity $(0$ to $10 \mathrm{~cm})$ and an acetylene production to nitrogen fixation conversion factor of 3

\begin{tabular}{|lcl|}
\hline Site & $\begin{array}{c}\text { Rate } \\
\left(\mathrm{mg} \mathrm{N} \mathrm{m} \mathrm{N}^{-2} \mathrm{~d}^{-1}\right)\end{array}$ & \multicolumn{1}{c|}{ Source } \\
\hline St. Croix: & & This study \\
uncolonized & 2.0 & \\
detritus deposit & 1.9 & \\
algal film & 4.5 & \\
Thallassia site & 13.6 & Corredor \& Capone \\
Puerto Rico: & $0.13-1.21$ & (1985) \\
& & Capone (1988) \\
Bermuda: & $0.74-3.40$ & \\
Various sea grass & $55-82$ & \\
Various subtidal & $0.4-15.3$ & \\
\hline
\end{tabular}

al. 1985, O'Neil \& Capone 1989). A comparison of these pool sizes with the estimated fixation rates (Fig. $11_{i}$ Table 2) suggests that an amount of ammonia equal to the standing stock could be fixed in a period of about 2 to $7 \mathrm{~d}$. Thus, nitrogenase activity could contribute significantly to nitrogen fluxes in tropical carbonate sediments. A similar conclusion has been reached by O'Neil \& Capone (1989). A more detailed analysis of nitrogen transformations and pool sizes will be required to establish the validity of this conclusion for the Salt River Canyon system.

Some of the potential controls of nitrogen fixation (acetylene reduction) were revealed by a time-course analysis of ethylene production associated with Dictyota $\mathrm{sp}$. detritus collected in the canyon from a depth of about $20 \mathrm{~m}$ (Fig. 13). During this time course, the highest rates of acetylene reduction were observed for detritus that was incubated anaerobically; under these conditions, ethylene production also proceeded with no apparent lag. Rates under aerobic conditions were relatively low and exhibited a lag of about $12 \mathrm{~h}$; the increase after this point could have been due to oxygen depletion in microzones (e.g. Paerl \& Carlton 1988) as

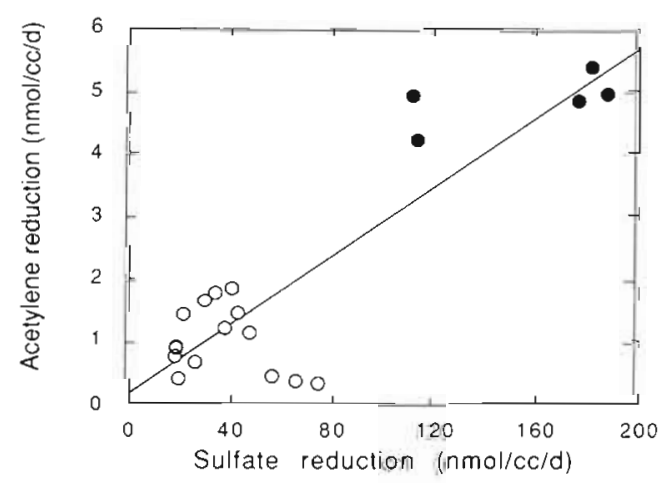

Fig. 12. Acetylene reduction rates versus sulfate reduction rates. (•) Triton Bay seagrass site; () pooled Salt River Canyon sites. Points are taken from parallel analyses of depth profiles for both processes

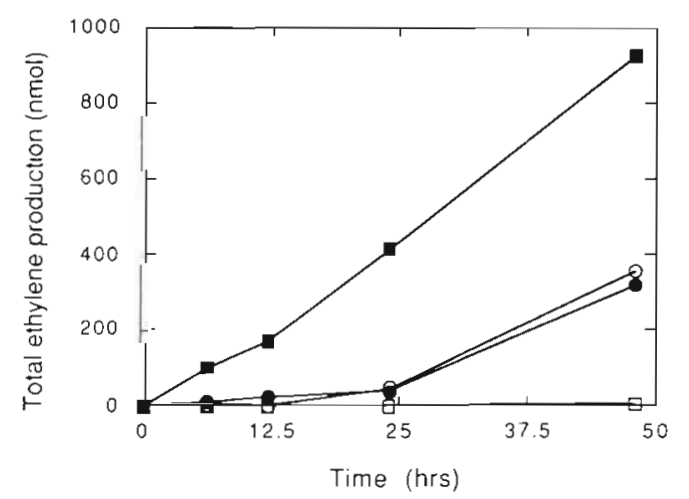

Fig. 13. Time course of ethylene production from Dictyota spp. detritus ( $1.0 \mathrm{~g}$ fresh weight) incubated in triplicate under various conditions: (1) aerobic controls; $(\bullet)$ aerobic $+\mathrm{MSX}_{i}$ (†) aerobic $+\mathrm{NH}_{4} \mathrm{Cl}_{i}(\mathbf{-})$ anaerobic 
the detritus samples were incubated without shaking. In another aerobic incubation, detritus was incubated with $10 \mu \mathrm{M} \mathrm{L}$-methionine-D, L-sulfoximine (MSX), an inhibitor of glutamine synthase which can reverse nitrogenase repression due to ammonia (e.g. Yoch \& Whiting 1986, Capone 1988). During the $48 \mathrm{~h}$ incubation period, MSX had no significant effect on ethylene production which suggests that ammonia repression was not an important limitation for detritus-associated acetylene reduction. Though MSX was used at a lower concentration in this study than in work reported by Capone (1988), Yoch \& Whiting (1986) reported that the inhibitor was quite effective at similar levels $(25 \mu \mathrm{M})$ in salt marsh sediments with relatively high ammonia concentrations.

Although MSX had no effect, a final aerobic treatment demonstrated the potential for repression. The addition of $1 \mathrm{mM}$ ammonia completely inhibited ethylene production (Fig. 13). Ammonia inhibition has been reported by others as well (e.g. Patriquin \& Knowles 1975, Corredor \& Capone 1985, O'Neil \& Capone 1989). However, it must be noted that the extent and nature of inhibition can be quite variable and depend-

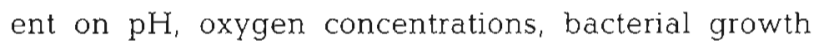
state, respiration rate, and carbon sources (Gordon et al. 1981, Gotto \& Yoch 1982, Klugkist \& Haaker 1984).

The results of the above analyses suggest that rates of nitrogen fixation associated with macroalgal detritus at the sediment-water interface may be low even though the detritus represents a potential source of organic substrate for nitrogen-fixing bacteria. Significant fixation is probably limited by the oxic conditions of the water column rather than by other factors. Similar conclusions about controls of detrital nitrogen fixation in the water column have been reached by Paerl \& Carlton (1988). These results do differ somewhat from those of Capone et al. (1977) who examined nitrogen fixation associated with Dictyota and Microdictyon sp. from a reef environment. Capone et al, (1977) found light-enhanced fixation which was inhibited by anoxia. They attributed nitrogen fixation to cyanobacterial epiphytes associated with the macroalgae. Differences between the 2 studies very likely reflect differences in the growth state of the macroalgae: Capone et al. (1977) collected samples of intact algae growing on the reef while samples for the study reported here were of detached and scenescent algae.

As with detritus at the sediment-water interface, nitrogen fixation in canyon surface sediments may be regulated by the presence of oxygen. Patriquin \& Knowles (1975) have suggested that nitrogen fixation is sensitive to the presence of oxygen and that the process is limited to anoxic microzones in aerobic sediments. They also suggested that aerobic diazotrophs were scarce and that nitrogen fixation was primarily due to a variety of anaerobes. O'Neil \& Capone (1989) found a variable response to oxygen during aerobic and anaerobic incubations, but they could not evaluate the importance of microzones.

Below the oxic zone, carbon availability is probably the most important factor regulating fixation. Ammonia repression could be of some significance if ammonia accumulates to concentrations greater than a few hundred micromolar (Capone 1988). However, both earlier and more recent evidence (Williams et al. 1985, O'Neil \& Capone 1989, Blackburn et al. pers. comm.) shows concentrations of only tens of micromolar or less, which are well below the threshold for inhibition suggested by Capone (1988) and within the range where Patriquin \& Knowles (1975) observed only limited effects. Thus, the availability of substrate would appear to be a key rate-determining parameter. Similar controls for nitrogen fixation (e.g. carbon and oxygen) have been proposed by Patriquin \& Knowles (1975), Capone \& Taylor (1980), and O'Neil \& Capone (1989).

In summary, our results support the following conclusions regarding benthic metabolism in Salt River Canyon:

(1) Oxygen distributions in canyon sediments are variable but tend to decrease to undetectable levels within millimeters. The distribution of oxygen is sensitive to physical conditions in the canyon which affect advective exchanges of porewater and resuspension; under highly turbulent conditions, oxygen penetration increases substantially relevant to more quiescent periods.

(2) Rates of sulfate reduction in surface sediments may be determined by benthic production as indicated by a correlation with chlorophyll; however in deeper layers, rates may be determined by the availability of buried organic matter. In general, both rates of sulfate reduction and the pool sizes of reduced sulfur endproducts (e.g. metal sulfides) are significantly less in canyon sediments than in the shallower and more organic-rich sediments of Triton Bay. The differences in sulfur pool sizes may reflect greater reoxidation due to more extensive bioturbation or physical mixing of the canyon sediments.

(3) Nitrogen fixation (acetylene reduction) also occurs in the canyon sediments. The distribution of acetylene reduction parallels that of sulfate reduction and is very likely sensitive to the same controls (e.g. dissolved oxygen concentrations and organic matter availability). Acetylene reduction associated with the organic-rich detritus that collects on the surface of the canyon floor is probably not significant since anoxic conditions are required before rates are stimulated. Those conditions do not exist at the sediment-water interface. However, rates associated with detritus may increase substantially after burial. 
Acknowledgements. We thank the staff of the National Undersea Research Program, U.S. Virgin Islands and the staff of the Farleigh Dickinson University West Indies Laboratory for invaluable support. We thank Drs Wells and Losee for excellent diving and technical assistance and Drs Mayer and Watling for helpful discussions. Drs D. Capone and G. Skyring provided constructive comments which improved the manuscript. We acknowledge the financial support of NOAA Grant nos. 40AANR501947 and NA88AA-H-UR020 and NSF nos. OCE-8700873 and BSR-8705342

\section{LITERATURE CITED}

Capone, D. G. (1982). Nitrogen fixation (acetylene reduction) by rhizosphere sediments of the eelgrass Zostera marina Mar. Ecol. Prog. Ser. 10:67-75

Capone, D. G. (1988). Benthic nitrogen fixation. In: Blackburn, T. H., Sorensen, J. (eds.) Nitrogen cycling in coastal marine environments. J. Wiley and Sons, Inc., New York, p. $85-123$

Capone, D. G., Taylor, B. F. (1980). $\mathrm{N}_{2}$ fixation in the rhizosphere of Thallassia testudinum. Can. J. Microbiol. 26: 998-1005

Capone, D. G., Carpenter, E. J. (1982). Perfusion method for assaying microbial activities in sediments: applicability to studies of $\mathrm{N}_{2}$ fixation by $\mathrm{C}_{2} \mathrm{H}_{2}$ reduction. Appl. envir] Microbiol. 43: 1400-1405

Capone, D. G., Taylor, D. L., Taylor, B. F. (1977). Nitrogen fixation (acetylene reduction) associated with macroalgae in a coral-reef community in the Bahamas. Mar. Biol. 40: 29-32

Carlton, R. G., Wetzel, R. G. (1987). Distributions and fates of oxygen in periphyton communities. Can. J. Bot. 65: $1031-1037$

Cline, J. D. (1969). Spectrophotometric determination of hydrogen sulfide in natural waters. Limnol. Oceanogr 14: $454-458$

Corredor, J., Capone, D. G. (1985). Studies on nitrogen diagenesis in tropical carbonate environments. In: Gabrie, C., Toffart, J. L., Salvat, B. (eds.) Proc. Fifth Int. Coral Reef Congress, p. 395-399

David, K. A. V., Apte, S. K., Banerji, A., Thomas, J. (1980). Acetylene reduction assay for nitrogenase activity: gas chromatographic determination of ethylene per sample in less than one minute. Appl. envirl Microbiol. 39: $1078-1080$

Dicker, H. J., Smith, D. W (1980). Enumeration and relative importance of acetylene-reducing (nitrogen-fixing) bacteria in a Delaware salt marsh. A.ppl. envirl Microbiol. 39: $1019-1025$

Entsch, B., Boto, K. G., Sim, R. G., Wellington, J. T (1983). Phosphorus and nitrogen in coral reef sediments. Limnol. Oceanogr. 28: 465-476

Fenchel, T., Riedl, R. J. (1970). The sulphide system: a new brotic community underneath the oxidized layer of marine sand bottoms. Mar. Biol. 7. 255-268

Fossing. H., Jorgensen, B. B. (nn press). Measurement of bacterial sulfate reduction in sediments: evaluation of a single-step chromium reduction method. Biogeochemistry

Gordon, J. K., Shah, V K, Brill, W. J. (1981). Feedback inhibition of nitrogenase. J. Bacteriol. 148: 884-888

Gotto, J. W., Yoch, D. C. (1982). Regulation of Rhodospirillum rubrum nitrogenase activity. Properties and interconversion of active and inactive Fe protein. J. brol. Chem. 257 . $2868-2873$
Hesslein, R. H. (1976). An in situ sampler for close interval porewater studies. Limnol. Oceanogr. 21. 912-914

Hines, M. E., Lyons, W. B. (1982). Biogeochemistry of nearshore Bermuda sediments. 1. Sulfate reduction rates and nutrient generation. Mar. Ecol. Prog. Ser. 8: 87-94

Jørgensen, B. B. (1977). The sulfur cycle of a coastal marine sediment (Limfjorden, Denmark). Limnol. Oceanogr 22: $814-832$

Jorgensen, B. B., Cohen, Y. (1977). Solar lake (Sinai). 5. The sulfur cycle of the benthic cyanobacterial mats. Limnol Oceanogr. 22: 657-666

King, G. M. (1988). Patterns of sulfate reduction and the sulfur cycle in a South Carolina salt marsh. Limnol. Oceanogr 33: $376-390$

King, G. M., Howes, B. L., Dacey, J. W. H. (1.985). Short-term endproducts of sulfate reduction in a salt marsh. the significance of acid volatile sulfide, elemental sulfur, and pyrite. Geochim cosmochim. Acta 49: 1561-1566

Klugkist, J., Haaker, H. (1984). Inhibition of nitrogenase activity by ammonium chloride in Azotobacter vinelandii. J. Bacteriol. 157: 148-151

Lorenzen, C. J. (1967). Determination of chlorophyll and pheo-pigments: spectrophotometric equations. Limnol. Oceanogr 12: 343-346

Multer, H. G., Gerhard, L. C. (1974). Guidebook to the geology and ecology of some terrestrial and marine environments. Fairleigh Dickinson University, St. Croix, U.S. Virgin Islands

Nedwell, D. B., Azin bin Abdul Aziz, S. (1980). Heterotrophic nitrogen fixation in an intertidal salt marsh sediment Estuar. cstl mar. Sci. 10: 699-702

O'Neil, J. M. Capone, D. G. (1989). Nitrogenase activity in tropical carbonate marine sediments. Mar. Ecol. Prog. Ser. 56: $145-156$

Paerl, H. W., Carlton, R. G. (1988). Control of nitrogen fixation by oxygen depletion in surface-associated microzones Nature, Lond. 332: 260-262

Patriquin, D. G., Knowles, R. (1975). Effects of oxygen, mannitol and ammonium concentrations on nitrogenase $\left[\mathrm{C}_{2} \mathrm{H}_{2}\right]$ activity in a marine skeletal carbonate sand. Mar. Biol. 32 49-62

Pigott, J. D., Land, L. S. (1986). Interstitial water chemistry of Jamaican reef sediment: sulfate reduction and submarine cementation. Mar Chem. 19: 355-378

Postgate, J. R. (1982a). The sulphate-reducing bacteria. Cambridge University Press, Cambridge

Postgate, J. R. (1982b). The fundamentals of nitrogen fixation. Cambridge University Press, Cambridge

Postgate, J. R., Kent, H. M. (1984). Derepression of nitrogen fixation in Desulfovibrio gigas and its stability to ammonia or oxygen stress in vivo. J. gen. Microbiol. 130: 2825-283.

Revsbech, N. P., Jørgensen, B. B. (1986). Microelectrodes their use in microbial ecology. Adv microb. Ecol. $y$ : 293-352

Skyring, G. W. (1985). Microbial anaerobic processes in coral reef sediments. In: Gabrie, C., Toffart, J. L., Salvat, B. (eds.) Proc. Fifth Int. Coral Reef Congress, p. 421-425

Skyring, G. W. (1987). Sulfate reduction in coastal ecosystems. Geomicrobiol. J. 5: 295-374

Skyring, G. W., Chambers, L. A. (1976), Biological sulfate reduction in carbonate sediments of a coral reef. Aust. J. mar. Freshwat. Res. 27. 595-602

Tabatabai, M. A. (1974). Determination of sulfate in water samples. Sulphur Inst. J. 10: 11-13

Thode-Andersen, S., Jorgensen, B. B. (1989). Sulfate reduction and the formation of ${ }^{35} \mathrm{~S}$-labelled $\mathrm{FeS}, \mathrm{FeS}_{2}$ and $\mathrm{S}^{0}$ in coastal marine sediments. Limnol. Oceanogr. 34: 793-806 
Waslenchuk, D. G., Matson, E. A., Zajac, R. N., Dobbs, F. C., Tramontano, J. M. (1983). Geochemistry of burrow waters vented by a bioturbating shrimp in Bermudian sediments. Mar. Biol. 72: 219-225

Williams, S. L., Yarish, S. M., Gill, l. P. (1985). Ammonium distributions, production, and efflux from backreef sedi-

This article was presented by Professor $T$ Fenchel, Helsingor, Denmark ments, St. Croix, U.S. Virgin Islands. Mar. Ecol. Prog. Ser. $24: 57-64$

Yoch, D. C., Whiting, G. J. (1986). Evidence for $\mathrm{NH}_{4}^{+}$switch-off regulation of nitrogenase activity by bacteria in salt marsh sediments and roots of the grass Spartina alterniflora. Appl. envirl Microbiol. 51. 143-149

Manuscript first received: March 8, 1989

Revised version accepted: September 5, 1989 